\title{
Child-Pugh B or C Cirrhosis Increases the Risk for Bleeding Following Colonoscopic Polypectomy
}

Hosim Soh ${ }^{1}$, Jaeyoung Chun ${ }^{1,2}$, Seung Wook Hong ${ }^{1}$, Seona Park ${ }^{1}$, Yun Bin Lee ${ }^{1}$, Hyun Jung Lee ${ }^{1}$, Eun Ju Cho ${ }^{1}$, Jeong-Hoon $\mathrm{Lee}^{1}$, Su Jong $\mathrm{Yu}^{1}$, Jong Pil $\mathrm{Im}^{1}$, Yoon Jun $\mathrm{Kim}^{1}$, Joo Sung Kim${ }^{1}$, and Jung-Hwan Yoon ${ }^{1}$

${ }^{1}$ Department of Internal Medicine and Liver Research Institute, Seoul National University College of Medicine, and ${ }^{2}$ Department of Internal Medicine, Gangnam Severance Hospital, Yonsei University College of Medicine, Seoul, Korea

Background/Aims: The risk for colonoscopic postpolypectomy bleeding (PPB) in patients with chronic liver disease $(C L D)$ remains unclear. We determined the incidence and risk factors for colonoscopic PPB in patients with CLD, especially those with liver cirrhosis. Methods: We retrospectively reviewed the medical records of patients with CLD who underwent colonoscopic polypectomy at Seoul National University Hospital between 2011 and 2014. The study endpoints were immediate and delayed PPB. Results: A total of 1,267 consecutive patients with CLD were included in the study. Immediate PPB occurred significantly more often in the ChildPugh (CP) B or C cirrhosis group (17.5\%) than in the CP-A (6.3\%) and chronic hepatitis (4.6\%) groups $(p<0.001)$. Moreover, the incidence of delayed PPB in the CP-B or $\mathrm{C}$ cirrhosis group (4.4\%) was significantly higher than that in the CP-A $(0.7 \%)$ and chronic hepatitis $(0.2 \%)$ groups $(p<0.001)$. The independent risk factors for immediate PPB were CP-B or C cirrhosis $(p=0.011)$, a platelet count $<50,000 / \mu \mathrm{L}(p<0.001)$, 3 or more polyps $(p=0.017)$, endoscopic mucosal resection or submucosal dissection $(p<0.001)$, and polypectomy performed by trainees $(p<0.001)$. The independent risk factors for delayed PPB were CP-B or $C$ cirrhosis $(p=0.009)$, and polyps $>10 \mathrm{~mm}$ in size $(p=0.010)$. Conclusions: Patients with CP-B or $\mathrm{C}$ cirrhosis had an increased risk for bleeding following colonoscopic polypectomy. (Gut Liver 2020;14:755764)

Key Words: Hepatitis, chronic; Chronic liver disease; Colonoscopy; Liver cirrhosis; Postpolypectomy bleeding

\section{INTRODUCTION}

Colonoscopic procedures for removal of colorectal adenomatous polyps are effective for primary and secondary prevention of colorectal cancers, but are associated with a risk for serious adverse events, such as postpolypectomy bleeding (PPB). PPB is the most common adverse event following a colonoscopic polypectomy, and its frequency ranges from $0.2 \%$ to $6.1 \% .^{1-5} \mathrm{PPB}$ may occur immediately after colonoscopic polypectomy or can be delayed up to 30 days after the procedure. A literature review identified, old age, underlying comorbidities such as hypertension, cardiovascular disease and chronic kidney disease, largesized polyps, and polyps located in the right-sided colon as known risk factors for colonoscopic PPB., ${ }^{3,6-9}$

Patients with chronic liver disease (CLD) have a tendency to bleed due to a disruption of coagulation factor synthesis in the liver, and this disruption is often accompanied by thrombocytopenia and portal hypertension. ${ }^{10,11}$ Previous studies indicated that patients with CLD are more prone to bleeding following an invasive procedure such as surgery or liver biopsy. ${ }^{12,13}$ However, the risk of bleeding following colonoscopic resection of colorectal polyps in patients with a CLD such as chronic hepatitis or liver cirrhosis (LC) has not been fully evaluated. This study investigated the incidence and risk factors for PPB, including immediate and delayed PPB, in patients with a CLD, and especially LC.

\section{MATERIALS AND METHODS}

\section{Patients}

From January 2011 to December 2014, the medical records of all patients with a CLD (e.g., chronic hepatitis or LC) who underwent a colonoscopic polypectomy at Seoul National University

Correspondence to: Jaeyoung Chun

Department of Internal Medicine, Gangnam Severance Hospital, Yonsei University College of Medicine, 20 Eonju-ro 63-gil, Gangnam-gu, Seoul 06229, Korea

Tel: +82-2-2019-3310, Fax: +82-2-3463-3882, E-mail: chunjmd@yuhs.ac

Received on April 22, 2019. Revised on September 22, 2019. Accepted on October 11, 2019. Published online December 11, 2019. pISSN 1976-2283 eISSN 2005-1212 https://doi.org/10.5009/gnl19131

() This is an Open Access article distributed under the terms of the Creative Commons Attribution Non-Commercial License (http://creativecommons.org/licenses/by-nc/4.0) which permits unrestricted non-commercial use, distribution, and reproduction in any medium, provided the original work is properly cited. 
Hospital were reviewed retrospectively. Patients with CLD were defined as those who had displayed evidence of hepatic insult for $>6$ months. The etiologies of CLD were identified by reviewing each patient's medical history, serologic laboratory findings including viral and autoimmune markers, and abdominal imaging results, including abdominal ultrasonography, computed tomography, magnetic resonance imaging, and/or liver biopsy. Patients with viral hepatitis were identified with serologic markers. Patients with alcoholic liver disease were identified with history of excessive alcohol consumption within 6 months (more than $60 \mathrm{~g} /$ day for male and $40 \mathrm{~g} /$ day for female) and exclusion of viral hepatitis, systemic autoimmune diseases, and metabolic diseases. Nonalcoholic fatty liver disease was defined as the presence of fatty liver in abdominal imaging, a history of daily alcohol intake less than $20 \mathrm{~g} /$ day and exclusion of viral hepatitis, systemic autoimmune diseases, and metabolic diseases. ${ }^{14,15}$ The diagnosis of LC was based on abdominal imaging findings, liver histology and/or clinical signs of portal hypertension such as the presence of ascites, esophageal or gastric varices, and hepatic encephalopathy. ${ }^{16-18}$ The patient information collected for the study included data regarding age, sex, laboratory findings such as serum albumin, total bilirubin, prothrombin time, and platelet counts, Child-Pugh (CP) scores, number, size, and location of the polyps, underlying diseases (diabetes mellitus, hypertension, dyslipidemia, coronary heart disease, cerebrovascular disease, and chronic kidney disease), and whether the patient was taking concomitant antiplatelet and/or anticoagulant medications such as aspirin, clopidogrel, ticagrelor, cilostazol, heparin, low molecular weight heparin, warfarin, or a new oral anticoagulant. Patients with platelet count less than $20,000 / \mu \mathrm{L}$ were excluded from the colonoscopic procedure. Patients who received transfusions of fresh frozen plasma or platelet concentrates before the procedures were included and the corrected results of blood tests following transfusions were collected. Generally, patients taking antiplatelet and/or anticoagulant agents were advised to hold the medication as follows; aspirin for 7 days, clopidogrel, ticagrelor, and cilostazol for 5 days, heparin for 6 hours, low molecular weight heparin for 12 hours, warfarin for 3 to 5 days, and new oral anticoagulant for 1 to 2 days before the colonoscopic procedures. Patients who discontinued the medication less than the advised interval were identified as those with concomitant medication. LC severity was classified into categories of $\mathrm{CP}$ class $\mathrm{A}$ to $\mathrm{C}$, based on each patient's CP score (CP-A, 5-6 points; CP-B, 7-9 points; CP-C, 10-15 points). ${ }^{19}$ This study adhered to the tenets of the Declaration of Helsinki. As the study did not include personal identifiers and was of a retrospective observational nature, informed consent was waived, and the study protocol was approved by the Seoul National University Hospital Institutional Review Board (IRB number: H-1807-042-957).

\section{Procedures}

Colonoscopy was performed with a standard colonoscope (CF H260AL; Olympus, Tokyo, Japan). In general, 2 L of polyethylene glycol solution was used for bowel preparation. Colorectal polyps detected during the procedure were removed by one of the following methods: cold forceps polypectomy, endoscopic mucosal resection (EMR), or endoscopic submucosal dissection (ESD). EMR was performed to resect polyps $>4 \mathrm{~mm}$ in diameter, and ESD was indicated for polyps $>20 \mathrm{~mm}$ in diameter, for which resection with snare EMR would be difficult. The injectand-cut technique was used for EMR. Epinephrine solution diluted with saline containing indigo carmine was administered as a subcutaneous injection given with a NM-4U-1 needle (Olympus). After elevating the polyp from the mucosa, a wire snare (SD-12L/U-1; Olympus) was used to enclose and grasp the polyp, and a cutting and coagulating electrical current was applied. For ESD, the area surrounding the polyp was marked with a dual knife (KD-650U; Olympus) that administered electrical coagulation (20W, VIO 300D; Erbe, Tübingen, Germany). Epinephrine diluted with saline containing indigo carmine was injected into the area, and consequently, the polyp was resected and submucosa was dissected using a dual knife. ${ }^{20}$ All colonoscopic procedures were performed by five expert endoscopists and 38 colonoscopy trainees. Expert endoscopists were defined as experienced endoscopists who performed $>1,000$ colonoscopies.

\footnotetext{
27,881 Patients underwent colonoscopic procedures (2011 to 2014)

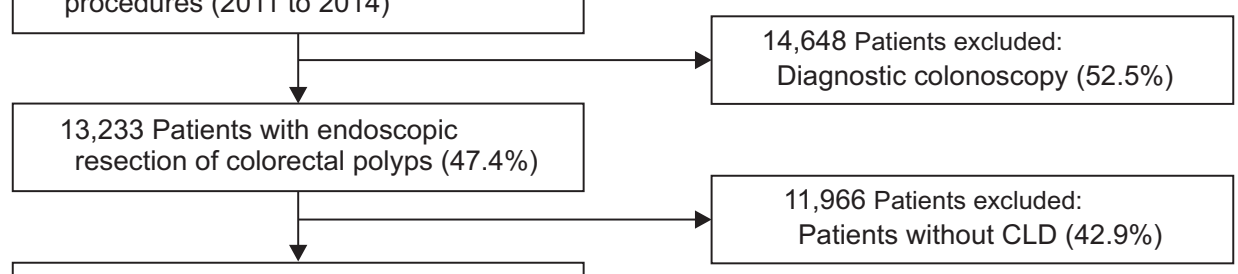

1,267 Patients with CLD (4.5\%)

453 Patients with chronic hepatitis $(1.6 \%)$

700 Patients with CP-A cirrhosis $(2.5 \%)$

100 Patients with CP-B cirrhosis $(0.4 \%)$

14 Patients with CP-C cirrhosis $(0.05 \%)$

Fig. 1. Study flowchart. CLD, chronic liver disease; CP, Child-Pugh.
} 
Table 1. Baseline Characteristics of the Study Population

\begin{tabular}{|c|c|c|c|c|c|}
\hline \multirow{2}{*}{ Baseline characteristics } & \multirow{2}{*}{$\begin{array}{l}\text { Chronic hepatitis } \\
\qquad(\mathrm{n}=453)\end{array}$} & \multicolumn{3}{|c|}{ Liver cirrhosis } & \multirow{2}{*}{ p-value } \\
\hline & & CP class A $(n=700)$ & CP class B $(n=100)$ & $\mathrm{CP}$ class $\mathrm{C}(\mathrm{n}=14)$ & \\
\hline Age, yr & $61.2 \pm 8.5$ & $62.4 \pm 9.0$ & $60.9 \pm 10.9$ & $51.8 \pm 7.1$ & $<0.001$ \\
\hline Male sex & $317(70.0)$ & 515 (73.6) & $69(69.0)$ & $11(78.6)$ & 0.471 \\
\hline Serum albumin, g/dL & $4.37 \pm 0.37$ & $4.17 \pm 0.42$ & $3.28 \pm 0.61$ & $2.54 \pm 0.51$ & $<0.001$ \\
\hline Serum total bilirubin, $\mathrm{mg} / \mathrm{dL}$ & $0.99 \pm 0.45$ & $1.16 \pm 0.54$ & $2.59 \pm 3.03$ & $11.06 \pm 10.84$ & $<0.001$ \\
\hline Prothrombin time, INR & $1.033 \pm 0.470$ & $1.091 \pm 0.127$ & $1.281 \pm 0.290$ & $2.200 \pm 1.130$ & $<0.001$ \\
\hline PLT count, $\times 10^{3} / \mu \mathrm{L}$ & $204.9 \pm 57.1$ & $138.8 \pm 63.4$ & $85.9 \pm 47.9$ & $84.9 \pm 42.1$ & $<0.001$ \\
\hline Patients with PLT $<50,000 / \mu \mathrm{L}$ & 0 & $34(4.9)$ & $16(16.0)$ & 0 & $<0.001$ \\
\hline CP score & & $5.2 \pm 0.4$ & $7.5 \pm 0.7$ & $11.6 \pm 1.4$ & $<0.001$ \\
\hline Cause of CLD & & & & & $<0.001$ \\
\hline HBV & $313(69.1)$ & $518(74.0)$ & $61(61.0)$ & $9(64.3)$ & \\
\hline $\mathrm{HCV}$ & $62(13.7)$ & $73(10.4)$ & $16(16.0)$ & 0 & \\
\hline Alcoholic & $40(8.8)$ & $25(3.6)$ & $9(9.0)$ & $4(28.6)$ & \\
\hline NAFLD & $22(4.9)$ & $22(3.1)$ & $6(6.0)$ & 0 & \\
\hline Autoimmune & $2(0.4)$ & $10(1.4)$ & $1(1.0)$ & 0 & \\
\hline Cryptogenic & $14(3.1)$ & $52(7.4)$ & $7(7.0)$ & $1(7.1)$ & \\
\hline Polyp no. & $2.3 \pm 2.0$ & $2.3 \pm 1.9$ & $2.6 \pm 2.2$ & $1.5 \pm 0.8$ & $<0.001$ \\
\hline Polyp size, $\mathrm{mm}$ & $5.5 \pm 3.8$ & $6.2 \pm 4.8$ & $6.8 \pm 4.7$ & $6.2 \pm 5.9$ & $<0.001$ \\
\hline Polyp $\geq 10 \mathrm{~mm}$ & $55(12.1)$ & $117(16.7)$ & $20(2.0)$ & $4(28.6)$ & 0.045 \\
\hline Method of polypectomy & & & & & 0.132 \\
\hline CFP & $205(45.3)$ & 305 (43.6) & 39 (39.0) & $10(71.4)$ & \\
\hline EMR or ESD & $248(54.7)$ & $395(56.4)$ & $61(61.0)$ & $4(28.6)$ & \\
\hline Location of polyp & & & & & 0.001 \\
\hline Proximal & $188(41.5)$ & $261(37.3)$ & $33(33.0)$ & $1(7.1)$ & \\
\hline Distal & $122(26.9)$ & $231(33.0)$ & $30(30.0)$ & $11(78.6)$ & \\
\hline Mixed & $143(31.6)$ & $208(29.7)$ & 37 (37.0) & $2(14.3)$ & \\
\hline Endoscopist & & & & & 0.195 \\
\hline Expert & $127(28.0)$ & $165(23.6)$ & $21(21.0)$ & $2(14.3)$ & \\
\hline Trainee & $326(72.0)$ & $535(76.4)$ & 79 (79.0) & $12(85.7)$ & \\
\hline \multicolumn{6}{|l|}{ Underlying disease } \\
\hline DM & $102(22.5)$ & $181(25.6)$ & $32(32.0)$ & $4(28.6)$ & 0.219 \\
\hline Hypertension & $157(34.7)$ & $199(28.4)$ & $21(21.0)$ & 0 & 0.002 \\
\hline Dyslipidemia & $107(23.6)$ & $50(7.1)$ & 0 & 0 & $<0.001$ \\
\hline $\mathrm{CHD}$ & $28(6.2)$ & $24(3.4)$ & 0 & 0 & 0.014 \\
\hline CVD & $13(2.9)$ & $11(1.6)$ & $1(1.0)$ & 0 & 0.354 \\
\hline CKD & $42(9.3)$ & $45(6.4)$ & $13(13.0)$ & $2(14.3)$ & 0.059 \\
\hline \multicolumn{6}{|l|}{ Concomitant medication } \\
\hline Aspirin & $43(9.5)$ & $26(3.7)$ & 0 & 0 & $<0.001$ \\
\hline Clopidogrel & $6(1.3)$ & $3(0.4)$ & 0 & 0 & 0.259 \\
\hline Cilostazol & $2(0.4)$ & $3(0.4)$ & 0 & 0 & 0.919 \\
\hline
\end{tabular}

Data are presented as mean \pm SD or number $(\%)$.

CP, Child-Pugh; INR, international normalized ratio; PLT, platelet; CLD, chronic liver disease; HBV, hepatitis B virus; HCV, hepatitis C virus; NAFLD, nonalcoholic fatty liver disease; CFP, cold forceps polypectomy; EMR, endoscopic mucosal resection; ESD, endoscopic submucosal dissection; DM, diabetes mellitus; CHD, coronary heart disease; CVD, cerebrovascular disease; CKD, chronic kidney disease. 


\section{Definitions}

The study endpoints were immediate and delayed PPB following colonoscopic resection for colorectal polyps. Immediate PPB was defined as development of bleeding from a polypectomy site during the colonoscopic procedure, for which hemostasis with hemoclipping, electrocauterization, and/or epinephrine injection was required. Delayed PPB was defined as the presentation of melena or hematochezia within 30 days of the colonoscopic procedure, with the symptoms requiring hospitalization or a hemostasis procedure. ${ }^{21,22}$ Clinical outcomes related to PPB following the colonoscopic removal of colorectal polyps, including need for colonoscopic hemostasis, surgical intervention, and mortality, were also evaluated.

\section{Statistical analysis}

All numerical values are expressed as the mean \pm standard deviation, or number (percent). Continuous variables were compared using the Student t-test. Categorical variables, both twoway and ordinal categories, were compared using the chi-square test. Independent risk factors for PPB were analyzed using the logistic regression models. Adjusted odds ratios (ORs) and 95\% confidence intervals (CIs) were calculated to estimate the effect of the variables in multivariate logistic regression models. A p-value $<0.05$ was considered statistically significant. All statistical analyses were performed using IBM SPSS Statistics for Windows, version 23.0 (IBM Corp., Armonk, NY, USA).

\section{RESULTS}

\section{Demographics}

From January 2011 to December 2014, colonoscopic procedures were performed in 27,881 patients at Seoul National University Hospital, and among them, 13,223 patients (47.4\%) underwent endoscopic resection of colorectal polyps. Among the patients treated for colorectal polyps, 1,267 consecutive patients with accompanying CLD were enrolled in this study (Fig. 1). Baseline characteristics of the study population are summarized in Table 1. The study population comprised 453 (35.8\%) patients with chronic hepatitis, 700 (55.2\%) with CP-A cirrhosis, 100 (7.9\%) with CP-B, and 14 (1.1\%) with CP-C, respectively. The mean serum albumin level $(\mathrm{g} / \mathrm{dL})$ was $4.37 \pm 0.37$ in patients with chronic hepatitis, $4.17 \pm 0.42$ in patients with CP-A cirrhosis, $3.28 \pm 0.61$ in patients with $\mathrm{CP}-\mathrm{B}$ cirrhosis, and $2.54 \pm 0.51$ in patients with $\mathrm{CP}-\mathrm{C}$ cirrhosis $(\mathrm{p}<0.001)$. The mean serum total bilirubin level and the mean prothrombin time in the $\mathrm{CP}-\mathrm{C}$ cirrhosis group was significantly higher than those in the chronic hepatitis, $\mathrm{CP}-\mathrm{A}$, and $\mathrm{CP}-\mathrm{B}$ cirrhosis groups (both $\mathrm{p}<0.001$ ). The mean serum albumin level and mean platelet count in $\mathrm{CP}-\mathrm{C}$ cirrhosis group was significantly lower than those in the chronic hepatitis, $\mathrm{CP}-\mathrm{A}$, and $\mathrm{CP}-\mathrm{B}$ cirrhosis groups (both $\mathrm{p}<0.001$ ). Among the study population, 50 (3.9\%) patients with $\mathrm{CP}-\mathrm{A}$ or $\mathrm{B}$ cirrhosis showed a platelet count less than $50,000 / \mu \mathrm{L}$ (Supplementary Table 1). The mean $\mathrm{CP}$ score was $5.2 \pm 0.4$ in $\mathrm{CP}-\mathrm{A}$ cirrhosis, $7.5 \pm 0.7$ in $\mathrm{CP}-\mathrm{B}$ cirrhosis, and $11.6 \pm 1.4$ in $\mathrm{CP}-\mathrm{C}$ cirrhosis $(\mathrm{p}<0.001)$.

The mean number of polyps was $2.3 \pm 2.0$ in chronic hepatitis, $2.3 \pm 1.9$ in CP-A cirrhosis, $2.6 \pm 2.2$ in CP-B cirrhosis, and $1.5 \pm 0.8$ in $\mathrm{CP}-\mathrm{C}$ cirrhosis, respectively $(\mathrm{p}<0.001)$. The mean polyp size was $5.5 \pm 3.8 \mathrm{~mm}$ in chronic hepatitis, $6.2 \pm 4.8 \mathrm{~mm}$ in CP-A cirrhosis, $6.8 \pm 4.7 \mathrm{~mm}$ in $\mathrm{CP}-\mathrm{B}$ cirrhosis, and $6.2 \pm 5.9 \mathrm{~mm}$ in $\mathrm{CP}-\mathrm{C}$ cirrhosis $(p<0.001)$, respectively. The proportion of proximal colon polyps was significantly higher in the chronic hepatitis group compared to the cirrhosis groups, but the distal location was significantly associated with the $\mathrm{CP}-\mathrm{C}$ cirrhosis. With regard to underlying diseases, the prevalence of hypertension and dyslipidemia were significantly higher among patients with chronic hepatitis than among patients with $\mathrm{CP}-\mathrm{A}, \mathrm{B}$, and $\mathrm{C}$ cirrhosis ( $p=0.002$ and $p<0.001$, respectively). The chronic hepatitis group used significantly higher percentage of aspirin compared to the $\mathrm{CP}-\mathrm{A}, \mathrm{B}$, and $\mathrm{C}$ cirrhosis groups $(\mathrm{p}<0.001)$. None of the study participants were taking an anticoagulant such as low molecular weight heparin, warfarin, or new oral anticoagulant.

\section{Incidence and clinical outcomes of PPB}

Among the 1,267 patients with CLD, 95 (7.5\%) experienced PPB. The incidence of PPB was significantly higher among patients with $\mathrm{CP}-\mathrm{B}$ or C cirrhosis (21.9\%) than among patients with chronic hepatitis (4.9\%) or CP-A cirrhosis $(6.9 \%)(\mathrm{p}<0.001)$. Immediate PPB occurred in 85 patients (6.7\%). The incidence of immediate PPB was significantly higher among patients with CP-B or C cirrhosis (17.5\%) than among patients with chronic hepatitis $(4.6 \%)$ or CP-A cirrhosis $(6.3 \%)(\mathrm{p}<0.001)$ (Table 2). All of the patients with immediate PPB improved following colonoscopic electrocauterization, epinephrine spraying, hot biopsy forceps coagulation, and/or hemoclipping.

A total of 11 patients (0.9\%) experienced delayed PPB, and the incidence of delayed PPB was also significantly higher among patients with CP-B or C cirrhosis (4.4\%) than among patients those with chronic hepatitis (0.2\%) or CP-A cirrhosis (0.7\%) $(\mathrm{p}<0.001)$ (Table 2). All patients with delayed PPB underwent EMR or ESD for resection of polyps. Among the 11 patients

Table 2. PPB in Patients with Chronic Hepatitis and Liver Cirrhosis

\begin{tabular}{|c|c|c|c|c|}
\hline \multirow[b]{2}{*}{ Event } & \multirow{2}{*}{$\begin{array}{l}\text { Chronic } \\
\text { hepatitis } \\
(n=453)\end{array}$} & \multicolumn{2}{|c|}{ Liver cirrhosis } & \multirow[b]{2}{*}{ p-value } \\
\hline & & $\begin{array}{c}\text { CP class A } \\
(n=700)\end{array}$ & $\begin{array}{c}\text { CP class B, C } \\
(n=114)\end{array}$ & \\
\hline \multicolumn{5}{|l|}{ PPB (\%) } \\
\hline Total & 22 (4.9) & $48(6.9)$ & 25 (21.9) & $<0.001$ \\
\hline Immediate & $21(4.6)$ & $44(6.3)$ & $20(17.5)$ & $<0.001$ \\
\hline Delayed & $1(0.2)$ & $5(0.7)$ & $5(4.4)$ & $<0.001$ \\
\hline
\end{tabular}

PPB, postpolypectomy bleeding; CP, Child-Pugh. 
Table 3. Risk Factors for Immediate Postpolypectomy Bleeding

\begin{tabular}{|c|c|c|c|c|c|}
\hline \multirow{2}{*}{ Variable } & \multirow{2}{*}{$\begin{array}{c}\text { Incidence of } \\
\text { immediate PPB (\%) }\end{array}$} & \multicolumn{2}{|c|}{ Univariate analysis } & \multicolumn{2}{|c|}{ Multivariate analysis } \\
\hline & & OR $(95 \%$ CI) & p-value & OR $(95 \%$ CI $)$ & $\mathrm{p}$-value \\
\hline \multicolumn{6}{|l|}{ Sex } \\
\hline Male & $60(6.6)$ & 1 (reference) & & & \\
\hline Female & $25(7.0)$ & $1.076(0.663-1.745)$ & 0.767 & & \\
\hline Age, yr & & $0.99(0.967-1.104)$ & 0.425 & & \\
\hline \multicolumn{6}{|l|}{ Platelet count } \\
\hline$\geq 50,000 / \mu \mathrm{L}$ & $70(5.9)$ & 1 (reference) & & 1 (reference) & \\
\hline$<50,000 / \mu \mathrm{L}$ & $14(27.5)$ & 6.038 (3.118-11.690) & $<0.001$ & 6.617 (3.045-14.382) & $<0.001$ \\
\hline Chronic liver disease & & & $<0.001$ & & 0.011 \\
\hline $\mathrm{CH}$ & $21(4.6)$ & 1 (reference) & & 1 (reference) & \\
\hline $\mathrm{CP}$ class $\mathrm{A}$ & $44(6.3)$ & $1.38(0.809-2.353)$ & 0.237 & $0.977(0.554-1.722)$ & 0.935 \\
\hline $\mathrm{CP}$ class $\mathrm{B}, \mathrm{C}$ & $20(17.5)$ & 4.377 (2.281-8.399) & $<0.001$ & $2.483(1.204-5.122)$ & 0.014 \\
\hline \multicolumn{6}{|l|}{ No. of polyp } \\
\hline$<3$ & $36(4.0)$ & 1 (reference) & & 1 (reference) & \\
\hline$\geq 3$ & $49(13.0)$ & 3.529 (2.253-5.527) & $<0.001$ & 2.055 (1.136-3.717) & 0.017 \\
\hline \multicolumn{6}{|l|}{ Size of polyp, mm } \\
\hline$<10$ & $59(5.5)$ & 1 (reference) & & 1 (reference) & \\
\hline$\geq 10$ & $26(13.3)$ & $2.623(1.609-4.278)$ & $<0.001$ & $1.526(0.875-2.663)$ & 0.137 \\
\hline \multicolumn{6}{|c|}{ Method of polypectomy } \\
\hline CFP & $16(2.9)$ & 1 (reference) & & 1 (reference) & \\
\hline EMR or ESD & $25(6.3)$ & 3.665 (2.102-6.388) & $<0.001$ & 3.303 (1.694-6.437) & $<0.001$ \\
\hline Location of polyp & & & $<0.001$ & & 0.013 \\
\hline Proximal & $18(3.7)$ & 1 (reference) & & 1 (reference) & \\
\hline Distal & $20(5.1)$ & $1.381(0.720-2.649)$ & 0.331 & $1.445(0.720-2.898)$ & 0.300 \\
\hline Mixed & $47(12.1)$ & $3.54(2.020-6.203)$ & $<0.001$ & $1.981(1.021-3.845)$ & 0.043 \\
\hline \multicolumn{6}{|l|}{ Endoscopist } \\
\hline Expert & $12(3.8)$ & 1 (reference) & & 1 (reference) & \\
\hline Trainee & $73(7.7)$ & $2.097(1.123-3.915)$ & 0.020 & $3.462(1.786-6.709)$ & $<0.001$ \\
\hline \multicolumn{6}{|l|}{ Underlying diseases } \\
\hline $\mathrm{DM}$ & $27(8.5)$ & $1.419(0.882-2.282)$ & 0.149 & & \\
\hline Hypertension & $24(6.4)$ & $0.924(0.567-1.506)$ & 0.751 & & \\
\hline Dyslipidemia & $5(3.2)$ & $0.424(0.169-1.062)$ & 0.067 & & \\
\hline CHD & $1(1.9)$ & $0.264(0.036-1.934)$ & 0.190 & & \\
\hline CVD & $2(8.0)$ & $0.824(0.191-3.556)$ & 0.796 & & \\
\hline $\mathrm{CKD}$ & $8(7.8)$ & $1.203(0.564-2.566)$ & 0.633 & & \\
\hline \multicolumn{6}{|c|}{ Concomitant medication } \\
\hline Aspirin & $2(2.9)$ & $0.401(0.097-1.666)$ & 0.209 & & \\
\hline Clopidogrel & 0 & & 1.000 & & \\
\hline Cilostazol & 0 & & 1.000 & & \\
\hline
\end{tabular}

PPB, postpolypectomy bleeding; OR, odds ratio; CI, confidence interval; $\mathrm{CH}$, chronic hepatitis; $\mathrm{CP}$, Child-Pugh; CFP, cold forceps polypectomy; EMR, endoscopic mucosal resection; ESD, endoscopic submucosal dissection; DM, diabetes mellitus; CHD, coronary heart disease; CVD, cerebrovascular disease; CKD, chronic kidney disease. 
Table 4. Risk Factors for Delayed Postpolypectomy Bleeding

\begin{tabular}{|c|c|c|c|c|c|}
\hline \multirow{2}{*}{ Variable } & \multirow{2}{*}{$\begin{array}{c}\text { Incidence of } \\
\text { delayed PPB (\%) }\end{array}$} & \multicolumn{2}{|c|}{ Univariate analysis } & \multicolumn{2}{|c|}{ Multivariate analysis } \\
\hline & & OR $(95 \% \mathrm{CI})$ & p-value & OR $(95 \% \mathrm{CI})$ & p-value \\
\hline \multicolumn{6}{|l|}{ Sex } \\
\hline Male & $9(1.0)$ & 1 (reference) & & & \\
\hline Female & $2(0.6)$ & $0.568(0.122-2.644)$ & 0.471 & & \\
\hline Age, yr & & 0.957 (0.899-1.019) & 0.173 & & \\
\hline \multicolumn{6}{|l|}{ Platelet count } \\
\hline$\geq 50,000 / \mu \mathrm{L}$ & $9(0.8)$ & 1 (reference) & & 1 (reference) & \\
\hline$<50,000 / \mu \mathrm{L}$ & $2(4.1)$ & $5.342(1.124-25.388)$ & 0.035 & $5.354(0.779-36.823)$ & 0.088 \\
\hline Chronic liver disease & & & 0.002 & & 0.009 \\
\hline $\mathrm{CH}$ & $1(0.2)$ & 1 (reference) & & 1 (reference) & \\
\hline $\mathrm{CP}$ class $\mathrm{A}$ & $5(0.7)$ & $3.252(0.379-27.925)$ & 0.282 & $2.748(0.265-28.446)$ & 0.397 \\
\hline $\mathrm{CP}$ class $\mathrm{B}, \mathrm{C}$ & $5(4.4)$ & $20.734(2.398-179.283)$ & 0.006 & $19.715(1.736-223.875)$ & 0.016 \\
\hline \multicolumn{6}{|l|}{ No. of polyp } \\
\hline$<3$ & $3(0.3)$ & 1 (reference) & & 1 (reference) & \\
\hline$\geq 3$ & $8(2.1)$ & $6.386(1.685-24.203)$ & 0.006 & $2.918(0.658-12.936)$ & 0.159 \\
\hline \multicolumn{6}{|l|}{ Size of polyp, mm } \\
\hline$<10$ & $2(0.2)$ & 1 (reference) & & 1 (reference) & \\
\hline$\geq 10$ & $9(4.6)$ & 25.725 (5.515-119.998) & $<0.001$ & $8.274(1.662-41.205)$ & 0.010 \\
\hline \multicolumn{6}{|c|}{ Method of polypectomy } \\
\hline CFP & 0 & NA & & & \\
\hline EMR or ESD & $11(1.6)$ & NA & 1.000 & & \\
\hline Location of polyp & & & 0.519 & & \\
\hline Proximal & $4(0.8)$ & 1 (reference) & & & \\
\hline Distal & $2(0.5)$ & $0.611(0.111-3.353)$ & 0.571 & & \\
\hline Mixed & $5(1.3)$ & $1.555(0.415-5.831)$ & 0.513 & & \\
\hline \multicolumn{6}{|l|}{ Endoscopist } \\
\hline Expert & $4(0.4)$ & 1 (reference) & & 1 (reference) & \\
\hline Trainee & $7(2.2)$ & $0.186(0.054-0.638)$ & 0.008 & $0.306(0.074-1.255)$ & 0.100 \\
\hline \multicolumn{6}{|l|}{ Underlying diseases } \\
\hline DM & 0 & & 1.000 & & \\
\hline Hypertension & $1(0.3)$ & $0.234(0.030-1.835)$ & 0.167 & & \\
\hline Dyslipidemia & $1(0.6)$ & $0.705(0.090-5.546)$ & 0.740 & & \\
\hline CHD & 0 & & 1.000 & & \\
\hline CVD & $2(8.3)$ & $11.903(2.435-58.180)$ & 0.002 & $4.703(0.282-78.295)$ & 0.281 \\
\hline CKD & $2(2.0)$ & $2.569(0.548-12.052)$ & 0.232 & & \\
\hline \multicolumn{6}{|c|}{ Concomitant medication } \\
\hline Aspirin & 0 & & 1.000 & & \\
\hline Clopidogrel & $1(11.1)$ & $15.600(1.781-136.628)$ & 0.013 & $9.567(0.152-601.475)$ & 0.285 \\
\hline Cilostazol & 0 & & 1.000 & & \\
\hline
\end{tabular}

PPB, postpolypectomy bleeding; OR, odds ratio; CI, confidence interval; $\mathrm{CH}$, chronic hepatitis; $\mathrm{CP}$, Child-Pugh; CFP, cold forceps polypectomy; EMR, endoscopic mucosal resection; ESD, endoscopic submucosal dissection; DM, diabetes mellitus; CHD, coronary heart disease; CVD, cerebrovascular disease; CKD, chronic kidney disease. 
with delayed PPB, 10 (90.9\%) required colonoscopic hemostasis, including electrocauterization, hot biopsy forceps coagulation, and/or hemoclipping. The other one patient refused any additional colonoscopic procedure, and the bleeding spontaneously subsided during hospitalization. No patient required surgical intervention, and no mortality related to PPB was found.

\section{Independent risk factors for PPB}

Our univariate analysis showed that immediate $\mathrm{PPB}$ was significantly associated with $\mathrm{CP}-\mathrm{B}$ or $\mathrm{C}$ cirrhosis $(\mathrm{p}<0.001)$, a platelet count $<50,000 / \mu \mathrm{L}(\mathrm{p}<0.001), 3$ or more polyps $(\mathrm{p}<0.001)$, a polyp size $\geq 10 \mathrm{~mm}(\mathrm{p}<0.001)$, mixed location of polyps $(\mathrm{p}<0.001)$, EMR or ESD $(\mathrm{p}<0.001)$, and polypectomy performed by trainees $(p=0.020)$ respectively. The multivariate analysis revealed that the independent risk factors for immediate PPB were CP-B or C cirrhosis (adjusted OR, 2.483; 95\% CI, 1.204 to 5.122; $\mathrm{p}=0.011$ ), a platelet count $<50,000 / \mu \mathrm{L}$ (adjusted OR, 6.617; 95\% CI, 3.045 to $14.382 ; \mathrm{p}<0.001$ ), 3 or more polyps (adjusted OR, 2.055; 95\% CI, 1.136 to 3.717; $\mathrm{p}=0.017$ ), EMR or ESD (adjusted OR, 3.303; 95\% CI, 1.694 to 6.437 ; $\mathrm{p}<0.001$ ), and polypectomy performed by trainees (adjusted OR, 3.462; 95\% CI, 1.786 to 6.709; $\mathrm{p}<0.001$ ) (Table 3).

In terms of the risk factors for delayed PPB, the univariate analysis showed that delayed PPB was significantly associated with CP-B or C cirrhosis ( $\mathrm{p}=0.002)$, a platelet count $<50,000$ / $\mu \mathrm{L}(\mathrm{p}=0.035), 3$ or more polyps ( $\mathrm{p}=0.006)$, a polyp size $\geq 10 \mathrm{~mm}$ $(p<0.001)$, polypectomy performed by experts $(p=0.008)$, the presence of cerebrovascular disease $(\mathrm{p}=0.002)$, and clopidogrel use $(p=0.013)$, respectively. The multivariate analysis showed that CP-B or C cirrhosis (adjusted OR, 19.715; 95\% CI, 1.736 to 223.875; $\mathrm{p}=0.009$ ), and a polyp size $\geq 10 \mathrm{~mm}$ (adjusted OR, 8.274; 95\% CI, 1.662 to 41.205; $\mathrm{p}=0.010$ ) were independent risk factors for delayed PPB (Table 4).

\section{DISCUSSION}

To the best of our knowledge, this is the largest cohort study to evaluate the incidence and risk factors for PPB following the colonoscopic resection of colorectal polyps in patients with CLD. Among the 1,267 patients with CLD, 114 patients with CP-B or $\mathrm{C}$ cirrhosis underwent endoscopic treatment for colorectal polyps. As a result, the overall incidence of PPB among patients with CLD was $7.5 \%$, which is higher than that incidence in the general population $(0.2 \%$ to $6.1 \%) .^{23,24}$ In this study, however, the incidence of PPB among patients with chronic hepatitis was $4.9 \%$, which is comparable with the risk for bleeding following colonoscopic polypectomy in the general population. Previous studies concerning the risk for bleeding following colonoscopic polypectomy have also shown that chronic hepatitis is not a significant risk factor for PPB. ${ }^{3,21}$ Patients with chronic hepatitis have decreased levels of most procoagulant factors, but the levels of naturally occurring anticoagulants such as antithrombin and protein $\mathrm{C}$ are also decreased in patients with chronic hepatitis, resulting in a balanced coagulant system similar to that found in healthy individuals. ${ }^{25}$

In this study, however, LC significantly increased the risk for both immediate and delayed PPB, according to CP scores. The incidence of delayed PPB among patients with CP-B or C cirrhosis was approximately 20-fold higher that that among patients with chronic hepatitis (4.4\%). This is consistent with results from a previous retrospective study of 152 patients with CLD. That study reported an increased incidence of delayed PPB (defined as $>1$ episode of hematochezia 6 hours to 30 days after colonoscopic polypectomy) among patients with LC when compared to patients with chronic hepatitis (13.8\% vs $4.2 \%) .{ }^{26}$ However, the incidence of delayed PPB in cases of CP-B or $\mathrm{C}$ cirrhosis was relatively lower in our study due to the different definition of delayed PPB. In terms of immediate PPB, a retrospective study of 30 patients with LC showed that LCrelated variables did not significantly increase the risk for immediate PPB, but that result was due to the small sample size. ${ }^{21}$ However, a retrospective study of 89 patients with LC indicated that patients with $\mathrm{CP}-\mathrm{B}$ or $\mathrm{C}$ cirrhosis were at a higher risk for immediate $\mathrm{PPB}{ }^{27}$ A recent retrospective study of 307 patients with LC, which included 44 patients with $\mathrm{CP}-\mathrm{B}$ or C cirrhosis, reported that the overall incidence of immediate $\mathrm{PPB}$ was 7.5\%, with a higher incidence of immediate PPB among CP-B or C LC patients (up to $13.6 \%$ ). Furthermore, the presence of ascites or esophageal varices significantly increased the risk for immediate $\mathrm{PPB}{ }^{28}$ In our largest cohort study that included 114 patients with $\mathrm{CP}-\mathrm{B}$ or $\mathrm{C}$ cirrhosis, the overall incidence of immediate PPB among CP-A cirrhosis patients was 6.3\%; however, CP-B or $\mathrm{C}$ cirrhosis patients were at an approximately 3-fold higher risk for immediate PPB when compared to $\mathrm{CP}-\mathrm{A}$ cirrhosis patients, which is consistent with the results of previous studies. LC, and especially decompensated cirrhosis, undoubtedly increases the risk for bleeding. ${ }^{25}$ This bleeding tendency among patients with cirrhosis is a product of several factors. Portal hypertension causes hemodynamic alterations, and high sialic acid concentrations hinder fibrinogen function. A bacterial infection or renal dysfunction may become superimposed on these abnormalities, and thereby aggravate a bleeding tendency. ${ }^{29-31}$ Taken together, patients with LC should be made aware of their increased risk for bleeding following a colonoscopic polypectomy, prior to undergoing the procedure. Moreover, any presentation of immediate or delayed PPB should be closely monitored in patients with LC, and especially in patients with CP-B or C cirrhosis.

Our current study showed that the risk for immediate PPB was significantly increased among CLD patients with a platelet count $<50,000 / \mu \mathrm{L}$. Among our patients with $\mathrm{CP}-\mathrm{B}, \mathrm{C}$ cirrhosis, and a platelet count $<50,000 / \mu \mathrm{L}$, the incidence of immediate PPB was $31.3 \%$ (data not shown). Immediate PPB is related to a dysfunction of primary hemostasis, which involves platelet aggregation and coagulation factors. ${ }^{32,33}$ Patients with decom- 
pensated cirrhosis have a diminished ability to synthesize coagulation factors in the liver, and exhibit thrombocytopenia and thrombocytopathy due to platelet sequestration, thrombopoietin deficiency, and low grade disseminated intravascular coagulation, all of which contribute to hemostatic abnormalities. ${ }^{34,35}$ In vitro studies have shown that thrombin generation, assessed as endogenous thrombin potential, can be secured with a platelet count $\geq 50,000 / \mu \mathrm{L},{ }^{36}$ indicating the necessity for a platelet transfusion prior to performing any invasive procedure such as a colonoscopic polypectomy in CP-B or C cirrhosis patients.

This study showed that multiple polyps, mixed proximal and distal colon polyps, colonoscopic polypectomies conducted via EMR or ESD, and those performed by trainees, were also independent risk factors for immediate PPB in patients with CLD. Previous studies have also identified several polyp-associated risk factors for immediate PPB; polyp number, size, and morphology are all well-established polyp-associated risk factors. ${ }^{1}$ Polypectomy performed with an advanced technique ${ }^{37}$ and the experience of the endoscopist ${ }^{38}$ have also been identified as risk factors for immediate PPB, which correlates with our findings. Increased risk for immediate PPB in polyps with mixed location may owe to the multiple number of polyps. Therefore, CLD patients, and especially those with $\mathrm{CP}-\mathrm{B}$ or $\mathrm{C}$ cirrhosis and risk factors for immediate PPB associated with certain characteristics of their polyps and advanced procedures, should be considered as being at a higher risk for immediate bleeding prior to undergoing a colonoscopic polypectomy.

In this study, a polyp size $\geq 10 \mathrm{~mm}$ and $\mathrm{CP}-\mathrm{B}$ or $\mathrm{C}$ cirrhosis were identified as independent risk factors for delayed PPB. The adjusted risks for delayed bleeding as determined by a polyp size $\geq 10 \mathrm{~mm}$ was approximately 1.526 -fold higher in patients with CLD, respectively. Delayed PPB may be related not only to direct damage of the blood vessels which perfuse the resected polyp, but also to some insufficiencies resulting from the tissue healing process or vascular regeneration. ${ }^{39}$ Cirrhosis induces defects of primary hemostasis and delayed tissue healing that result from cirrhosis-associated immune dysfunction and an increased level of systemic inflammation, ${ }^{40}$ which may result in an increased risk for delayed bleeding after colonoscopic polypectomy. Polyp size is a well-established risk factor for delayed PPB, as larger polyps would cause delays in tissue healing and vascular regeneration. ${ }^{39}$ Thus, close monitoring for delayed bleeding in large-sized polyps in patients with CLD, and especially cirrhosis, would be needed.

Our study has some limitations that should be mentioned. First, it was a single center, retrospective study, and consequently might have been affected by selection bias. Second, even though it was the largest cohort study of patients with LC, the effect of $\mathrm{CP}-\mathrm{C}$ cirrhosis compared to $\mathrm{CP}-\mathrm{A}$ and $\mathrm{B}$ cirrhosis on the risk for PPB could not be determined due to the small sample size. Third, data on shape and histologic findings of the polyps were not available. Pedunculated shape or advanced

neoplasm might lead to the additive risk of PPB in the patients with CLD. Fourth, Whether the incidence of PPB in the patients with CLD is significantly higher compared to the general population could not be evaluated, because the study population was limited to those with CLD in this study. Fifth, patients with a platelet count less than $50,000 / \mu \mathrm{L}$ were included in this retrospective study. The American Society for Gastrointestinal Endoscopy recommends a threshold of $50,000 / \mu \mathrm{L}$ before colonoscopic polypectomy despite a lack of evidence. ${ }^{41}$ We aimed to define the optimal cutoff of platelet counts for colonoscopic polypectomy as well as the high-risk group for PPB in the CLD population at risk of bleeding. Finally, some patients with LC required anticoagulation therapy for managing their portal vein thrombosis; however, any additive risk for PPB resulting from anticoagulant use among patients with CLD could not be evaluated in this study. Further prospective studies are required to determine how anticoagulant use affects the risk for bleeding in patients with a CLD and undergo colonoscopic polypectomy.

In conclusion, we found that patients with $\mathrm{CP}-\mathrm{B}$ or $\mathrm{C}$ cirrhosis had an increased risk for bleeding following a colonoscopic resection for colorectal polyps when compared to patients with chronic hepatitis. Therefore, patients with CP-B or C cirrhosis, and especially those with thrombocytopenia, or multiple or large-sized polyps resected by EMR or ESD, should be carefully monitored for any presentation of PPB.

\section{CONFLICTS OF INTEREST}

No potential conflict of interest relevant to this article was reported.

\section{AUTHOR CONTRIBUTIONS}

Study concept and design: H.S., S.W.H., J.C. Data acquisition: H.S., S.W.H., S.P. Data analysis and interpretation: H.S., J.C. Drafting of the manuscript: H.S., J.C. Critical revision of the manuscript for important intellectual content: J.C., Y.B.L., H.J.L., E.J.C., J.H.L., S.J.Y., J.P.I., Y.J.K., J.S.K., J.H.Y. Statistical analysis: H.S., J.C. Study supervision: J.C., Y.B.L., H.J.L., E.J.C., J.H.L., S.J.Y., J.P.I., Y.J.K., J.S.K., J.H.Y. All authors reviewed and approved the final manuscript.

\section{ORCID}

Hosim Soh

Jaeyoung Chun

Seung Wook Hong

Seona Park

Yun Bin Lee

Hyun Jung Lee

Eun Ju Cho

Jeong-Hoon Lee https://orcid.org/0000-0001-5107-6521 https://orcid.org/0000-0002-4212-0380 https://orcid.org/0000-0003-1440-9950 https://orcid.org/0000-0002-7281-0833 https://orcid.org/0000-0002-3193-9745 https://orcid.org/0000-0003-2764-9339 https://orcid.org/0000-0002-2677-3189 https://orcid.org/0000-0002-0315-2080 
Su Jong $\mathrm{Yu}$

Jong Pil Im

Yoon Jun Kim

Joo Sung Kim

Jung-Hwan Yoon https://orcid.org/0000-0001-8888-7977

https://orcid.org/0000-0003-1584-0160

https://orcid.org/0000-0001-9141-7773

https://orcid.org/0000-0001-6835-4735

https://orcid.org/0000-0002-9128-3610

\section{REFERENCES}

1. Heldwein W, Dollhopf M, Rösch T, et al. The Munich Polypectomy Study (MUPS): prospective analysis of complications and risk factors in 4000 colonic snare polypectomies. Endoscopy 2005;37:1116-1122.

2. Hui AJ, Wong RM, Ching JY, Hung LC, Chung SC, Sung JJ. Risk of colonoscopic polypectomy bleeding with anticoagulants and antiplatelet agents: analysis of 1657 cases. Gastrointest Endosc 2004;59:44-48.

3. Kim HS, Kim TI, Kim WH, et al. Risk factors for immediate postpolypectomy bleeding of the colon: a multicenter study. Am J Gastroenterol 2006;101:1333-1341.

4. Nelson DB, McQuaid KR, Bond JH, Lieberman DA, Weiss DG, Johnston TK. Procedural success and complications of large-scale screening colonoscopy. Gastrointest Endosc 2002;55:307-314.

5. Lee JM, Kim WS, Kwak MS, et al. Clinical outcome of endoscopic management in delayed postpolypectomy bleeding. Intest Res 2017;15:221-227.

6. Choung BS, Kim SH, Ahn DS, et al. Incidence and risk factors of delayed postpolypectomy bleeding: a retrospective cohort study. J Clin Gastroenterol 2014;48:784-789.

7. Kwon MJ, Kim YS, Bae SI, et al. Risk factors for delayed postpolypectomy bleeding. Intest Res 2015;13:160-165.

8. Zhang Q, An Sl, Chen Zy, et al. Assessment of risk factors for delayed colonic post-polypectomy hemorrhage: a study of 15553 polypectomies from 2005 to 2013. PLoS One 2014;9:e108290.

9. Amato A, Radaelli F, Dinelli M, et al. Early and delayed complications of polypectomy in a community setting: the SPoC prospective multicentre trial. Dig Liver Dis 2016;48:43-48.

10. Ferro D, Angelico F, Caldwell SH, Violi F. Bleeding and thrombosis in cirrhotic patients: what really matters? Dig Liver Dis 2012;44:275-279.

11. Biecker E. Portal hypertension and gastrointestinal bleeding: diagnosis, prevention and management. World J Gastroenterol 2013;19:5035-5050.

12. Poordad FF. Presentation and complications associated with cirrhosis of the liver. Curr Med Res Opin 2015;31:925-937.

13. Neeff H, Mariaskin D, Spangenberg HC, Hopt UT, Makowiec F. Perioperative mortality after non-hepatic general surgery in patients with liver cirrhosis: an analysis of 138 operations in the 2000s using Child and MELD scores. J Gastrointest Surg 2011;15:1-11.

14. Hayashi T, Saitoh S, Fukuzawa K, et al. Noninvasive assessment of advanced fibrosis based on hepatic volume in patients with nonalcoholic fatty liver disease. Gut Liver 2017;11:674-683.

15. Park MS, Hong S, Lim YL, Kang SH, Baik SK, Kim MY. Measuring intrahepatic vascular changes using contrast-enhanced ultrasonography to predict the prognosis of alcoholic hepatitis combined with cirrhosis: a prospective pilot study. Gut Liver 2018;12:555561.

16. Ratziu V, Charlotte F, Heurtier A, et al. Sampling variability of liver biopsy in nonalcoholic fatty liver disease. Gastroenterology 2005;128:1898-1906.

17. Heo JY, Kim BK, Park JY, et al. Multicenter retrospective risk assessment of esophageal variceal bleeding in patients with cirrhosis: an acoustic radiation force impulse elastography-based prediction model. Gut Liver 2019;13:206-214.

18. Kim MN, Hwang SG, Kim BK, et al. Liver cirrhosis, not antiviral therapy, predicts clinical outcome in cohorts with heterogeneous hepatitis b viral status. Gut Liver 2019;13:197-205.

19. Choi JH, Kim ER, Min BH, et al. The feasibility and safety of the endoscopic submucosal dissection of superficial gastric neoplastic lesions in patients with compensated liver cirrhosis: a retrospective study. Gut Liver 2012;6:58-63.

20. Seo JY, Chun J, Lee C, et al. Novel risk stratification for recurrence after endoscopic resection of advanced colorectal adenoma. Gastrointest Endosc 2015;81:655-664.

21. Jeon JW, Shin HP, Lee JI, et al. The risk of postpolypectomy bleeding during colonoscopy in patients with early liver cirrhosis. Surg Endosc 2012;26:3258-3263.

22. Hasegawa H, Bamba S, Takahashi K, et al. Efficacy and safety of cold forceps polypectomy utilizing the jumbo cup: a prospective study. Intest Res 2019;17:265-272.

23. Sawhney MS, Salfiti N, Nelson DB, Lederle FA, Bond JH. Risk factors for severe delayed postpolypectomy bleeding. Endoscopy 2008;40:115-119.

24. Sorbi D, Norton I, Conio M, Balm R, Zinsmeister A, Gostout CJ. Postpolypectomy lower GI bleeding: descriptive analysis. Gastrointest Endosc 2000;51:690-696.

25. Tripodi A, Mannucci PM. The coagulopathy of chronic liver disease. N Engl J Med 2011;365:147-156.

26. Lee HS, Park JJ, Kim SU, et al. Incidence and risk factors of delayed postpolypectomy bleeding in patients with chronic liver disease. Scand J Gastroenterol 2016;51:618-624.

27. Lee S, Park SJ, Cheon JH, et al. Child-Pugh score is an independent risk factor for immediate bleeding after colonoscopic polypectomy in liver cirrhosis. Yonsei Med J 2014;55:1281-1288.

28. Huang RJ, Perumpail RB, Thosani N, Cheung R, Friedland S. Colonoscopy with polypectomy is associated with a low rate of complications in patients with cirrhosis. Endosc Int Open 2016;4:E947E952.

29. Caldwell SH, Hoffman M, Lisman T, et al. Coagulation disorders and hemostasis in liver disease: pathophysiology and critical assessment of current management. Hepatology 2006;44:10391046.

30. Boks AL, Brommer EJ, Schalm SW, Van Vliet HH. Hemostasis and fibrinolysis in severe liver failure and their relation to hemorrhage. 
Hepatology 1986;6:79-86.

31. Montalto P, Vlachogiannakos J, Cox DJ, Pastacaldi S, Patch D, Burroughs AK. Bacterial infection in cirrhosis impairs coagulation by a heparin effect: a prospective study. J Hepatol 2002;37:463470.

32. Ghazi A, Grossman M. Complications of colonoscopy and polypectomy. Surg Clin North Am 1982;62:889-896.

33. Ma L, Elliott SN, Cirino G, Buret A, Ignarro LJ, Wallace JL. Platelets modulate gastric ulcer healing: role of endostatin and vascular endothelial growth factor release. Proc Natl Acad Sci U S A 2001;98:6470-6475.

34. Amarapurkar PD, Amarapurkar DN. Management of coagulopathy in patients with decompensated liver cirrhosis. Int J Hepatol 2011;2011:695470.

35. Hugenholtz GGC, Porte RJ, Lisman T. The platelet and platelet function testing in liver disease. Clin Liver Dis 2009;13:11-20.

36. Tripodi A, Primignani M, Mannucci PM. Abnormalities of hemostasis and bleeding in chronic liver disease: the paradigm is chal- lenged. Intern Emerg Med 2010;5:7-12.

37. Conio M, Repici A, Demarquay JF, Blanchi S, Dumas R, Filiberti R. EMR of large sessile colorectal polyps. Gastrointest Endosc 2004;60:234-241.

38. Rees CJ, Thomas Gibson S, Rutter MD, et al. UK key performance indicators and quality assurance standards for colonoscopy. Gut 2016;65:1923-1929.

39. Watabe H, Yamaji Y, Okamoto M, et al. Risk assessment for delayed hemorrhagic complication of colonic polypectomy: polyprelated factors and patient-related factors. Gastrointest Endosc 2006;64:73-78.

40. Albillos A, Lario M, Álvarez-Mon M. Cirrhosis-associated immune dysfunction: distinctive features and clinical relevance. J Hepatol 2014;61:1385-1396.

41. ASGE Standards of Practice Committee, Ben-Menachem T, Decker GA, et al. Adverse events of upper GI endoscopy. Gastrointest Endosc 2012;76:707-718. 